www.periodicos.unimontes.br/index.php/caminhosdahistoria

\title{
HISTÓRIA E RELAÇÕES DE GÊNERO: SOCIABILIDADE E SILENCIAMENTO DA VIOLÊNCIA DOMÉSTICA E CONJUGAL EM CARANGOLA
}

\author{
Érika Oliveira Amorim Tannus Cheim ${ }^{1}$ \\ Maria Beatriz Nader ${ }^{2}$
}

Resumo: Este texto apresenta parte dos dados da pesquisa de doutorado "Mulher e Patriarcado: um estudo de caso sobre a violência contra a mulher em Carangola - MG (2006-2016)" a qual analisa como o fenômeno do patriarcado ainda influi no comportamento de homens e mulheres e de que maneira o tipo de sociabilidade local influencia no silenciamento dos casos de violência de gênero, especificamente a violência conjugal. A fim de ampliar os debates sobre o tema da violência contra a mulher e, com enfoque em uma cidade do interior, este estudo de caso aliou metodologias qualitativas e quantitativas. Para tanto entrevistou dez mulheres que vivenciaram contextos de violência conjugal e, ainda aplicou 376 questionários fechados em diferentes pontos da cidade de Carangola em um mesmo período (corte transversal) no intuito de conhecer a realidade da violência contra a mulher e encontrar casos não notificados/denunciados. A análise dos dados produzidos pelo estudo identificou que há silenciamento da violência conjugal na cidade de Carangola determinada pelo tipo de sociabilidade local.

Palavras-chave: Patriarcado; violência de gênero contra a mulher; violência conjugal;

História das mulheres.

\begin{abstract}
This text presents part of the data from the doctoral research "Woman and Patriarchate: a case study on violence against women in Carangola - MG (2006-2016)" which analyzes how the phenomenon of patriarchy still influences the behavior of men and women and how the type of local sociability influences the silencing of cases of gender-based violence, specifically conjugal violence. In order to broaden the debates on the theme of violence against women and, focusing on a city in the interior, this case study combined qualitative and quantitative methodologies. For this purpose, he interviewed ten women who experienced contexts of conjugal violence and also applied 376 closed questionnaires in different parts of the city of Carangola in the same period (cross-section) in order to learn about the reality of violence against women and find unreported cases / reported. The analysis of the data produced by the study identified that there is a silencing of conjugal violence in the city of Carangola determined by the type of local sociability.
\end{abstract}

\footnotetext{
${ }^{1}$ Doutora em História Social das Relações Políticas pela Universidade Federal do Espírito Santo (UFES). Docente do Curso de História da Universidade do Estado de Minas Gerais (UEMG), Unidade Carangola. E-mail: erika.amorim@uemg.br. ORCID: https://orcid.org/0000-0002-3842-0882

${ }^{2}$ Professora Titular do Programa de Pós-Graduação em História Social das Relações Políticas da Universidade Federal do Espírito Santo (UFES). Coordenadora do Laboratório de Estudos de Gênero, Poder e Violência (LEG/UFES). E-mail: marxis@terra.com.br. ORCID: https://orcid.org/0000-0001-7462-7154
} 
Keywords: Patriarchy; gender-based violence against women; conjugal violence; History of women.

\section{Introdução}

A proximidade entre os moradores da cidade de Carangola, Minas Gerais, contribui para o mútuo controle social, vigilância e julgamento moral de comportamentos e ações, sobretudo das mulheres, e acredita-se que essas particularidades da região podem persuadir aquelas que vivem em contextos de violência conjugal, levando-as a viver sob um continuиm de agressões dos diversos tipos e a não denunciarem as violências cometidas por seus companheiros. Por ser considerado um problema de foro privado, a violência contra a mulher, é favorecida pela invisibilidade ou subnotificação de casos. Pouco se sabe a respeito daquelas que vivem em contextos rurais ou em locais situados no interior do Brasil. A fim de ampliar os debates sobre o tema da violência de gênero e, com enfoque em uma cidade do interior, o estudo de caso aliou metodologias qualitativas e quantitativas, já que a escolha de metodologias quali pode ser subordinada às necessidades de respostas de relações causais, nem sempre possíveis a partir de abordagens quanti. Essa opção opõe-se a ideia antitética entre os dois métodos e tem sido adotada por uma crescente comunidade de pesquisadores em ciências sociais (KIRSCHBAUM, 2013). Para tanto, entrevistou-se dez mulheres que vivenciaram situações de violência conjugal e estiveram ou não sob medidas protetivas de urgência e aplicou-se 376 questionários fechados em um só período (corte transversal), com intuito de encontrar casos de violência contra a mulher que ainda não haviam sido denunciados, dos quais foram selecionadas duas entrevistadas que agregaram o grupo que já havia sido entrevistado, completando o número de dez entrevistas.

\section{Caminhos da pesquisa}

Vive-se a persistência do poder patriarcal constantemente travestido e amparado no reducionismo da "ideologia de gênero", forte manobra atual para ampliar seus tentáculos em diversos segmentos da sociedade. E, assim, a cultura da violência de gênero é historicamente alimentada, sobretudo pelo desejo de controle sobre os corpos e suas subjetividades, e se manifestam nos inúmeros casos de violência que assistimos todos os dias, seja ao nosso redor, pelos noticiários televisivos ou pelos dispositivos tecnológicos das redes sociais. Pode-se dizer que a violência de gênero decorre da hegemonia masculina sobre a mulher, que por sua 
vez, se estende aos espaços simbólicos nos quais as relações homem-mulher se desenvolvem, sejam territorialmente nos âmbitos privados, ou fora deles.

A violência de gênero é compreendida como uma categoria de violência amplamente difundida e que caminha no sentido homem contra mulher, como alegam Saffioti e Almeida (1995). Essas autoras foram as primeiras a utilizar o termo, no livro "Violência de Gênero: poder e impotência", publicado em 1995. Nesse sentido, a violência de gênero abrange a violência doméstica e a violência intrafamiliar, conforme afirmam Saffioti e Almeida e Teles e Melo (TELES, MELO, 2002, p. 18). Isso porque a violência doméstica ocorre dentro de casa, entre pessoas da mesma família, "entre homens e mulheres, pais, mães e filhos, entre jovens e pessoas idosas" (TELES, MELO, 2002, p. 19), e a violência intrafamiliar extrapola os limites do domicílio, pois "um avô, cujo domicílio é separado do de seu (sua) neto(a), pode cometer violência, em nome da sagrada família, contra este(a) pequeno(a) parente(a) (SAFFIOTI, 2015, p.75-76).

Cabe ainda esclarecer, no bojo da categoria violência de gênero, a definição de violência conjugal. Grossi (1998) faz reflexões sobre a violência no vínculo afetivo-conjugal e versa que, ao privilegiar a categoria violência doméstica, são problematizadas as violências nas quais as mulheres são envolvidas no âmbito privado e que o confinamento delas nesse espaço legitimou a violência masculina no âmbito da conjugalidade, concebida por Grossi como o "projeto afetivo/emocional de duas pessoas não necessariamente vivendo sob o mesmo teto, nem tendo filhos" (Grossi, 1998, p. 298) e se fundamenta nas categorias amor e paixão, tidas, segundo a autora, nas culturas individualistas ocidentais modernas como "naturais" e como sentimentos obrigatórios para a união afetivo/conjugal. Assim sendo, Grossi acredita que a presença das violências física, sexual, emocional ou psicológica nas relações afetivo/conjugais é inerente às contradições do modelo hegemônico de conjugalidade ocidental na modernidade e, assim, amplia o foco da problemática da violência conjugal das relações heterossexuais para as relações homoeróticas ${ }^{3}$. Grossi discorre ainda que ao avaliar as violências nas relações conjugais permite-se alcançar maior visibilidade aos casos de violências. É o que se buscou na pesquisa que se apresenta, tendo em vista que, ao abordar as entrevistadas para o estudo, não se privilegiou relações conjugais formais, objetivando acessar o maior número possível de mulheres submetidas a relações conjugais violentas.

\footnotetext{
3 Grossi justifica o uso da categoria "homoerotismo", proposta por Jurandir Freire Costa, pois permite desconstruir a noção de homossexualidade como identidade fixa de um indivíduo atraído por pessoas do mesmo sexo para pensar a relação entre dois indivíduos do mesmo sexo como uma escolha do presente e não como determinação eterna. Sobre o assunto ver: COSTA, 1992.
} 
Inclui-se ainda, no entendimento sobre violência contra a mulher e no que concerne a precisão de conceitos, a tipificação das diferentes formas de violências, tendo-as como ruptura de vários tipos de integridade, como física, sexual, emocional e moral. Para esse estudo, levou-se em consideração a classificação dada pela Lei 11.430/2006 (Lei Maria da Penha) (BRASIL, 2006), que em seu artigo sete, define as formas de violência doméstica e familiar contra a mulher, como:

I - a violência física, entendida como qualquer conduta que ofenda sua integridade ou saúde corporal;

II - a violência psicológica, entendida como qualquer conduta que lhe cause dano emocional e diminuição da auto-estima ou que lhe prejudique e perturbe o pleno desenvolvimento ou que vise degradar ou controlar suas ações, comportamentos, crenças e decisões, mediante ameaça, constrangimento, humilhação, manipulação, isolamento, vigilância constante, perseguição contumaz, insulto, chantagem, ridicularização, exploração e limitação do direito de ir e vir ou qualquer outro meio que lhe cause prejuízo à saúde psicológica e à autodeterminação;

III - a violência sexual, entendida como qualquer conduta que a constranja a presenciar, a manter ou a participar de relação sexual não desejada, mediante intimidação, ameaça, coação ou uso da força; que a induza a comercializar ou a utilizar, de qualquer modo, a sua sexualidade, que a impeça de usar qualquer método contraceptivo ou que a force ao matrimônio, à gravidez, ao aborto ou à prostituição, mediante coação, chantagem, suborno ou manipulação; ou que limite ou anule o exercício de seus direitos sexuais e reprodutivos;

IV - a violência patrimonial, entendida como qualquer conduta que configure retenção, subtração, destruição parcial ou total de seus objetos, instrumentos de trabalho, documentos pessoais, bens, valores e direitos ou recursos econômicos, incluindo os destinados a satisfazer suas necessidades;

$\mathrm{V}$ - a violência moral, entendida como qualquer conduta que configure calúnia, difamação ou injúria.

Essas formas de violência sistematizadas pela Lei Maria da Penha remetem ao estudo da condição feminina e sustentam a problematização sobre as assimetrias nas relações entre homens e mulheres apoiadas pela naturalização de papéis sociais que restringem as mulheres aos espaços domésticos e vislumbra aos homens a atuação ativa nos espaços públicos e, consequentemente, agentes de ação da violência em seus diversos tipos.

A violência contra a mulher é considerada uma violação aos Direitos Humanos, mas o silenciamento ou a subnotificação de casos de violência conjugal é uma realidade e um grande obstáculo ao enfrentamento desse problema social e à implementação de rede de apoio e combate a esse fenômeno. O principal fator dificultador para as denúncias ainda é o consentimento social para que os homens exerçam sua dominação sobre as mulheres. Outro fator que corrobora com a subnotificação dos casos de violência está relacionado ao ordenamento familiar e ao fato de o agressor ser, possivelmente, o único provedor da família. 
Sua ausência, caso seja recluso em decorrência da denúncia por cometer violência contra a mulher, dificultaria a sobrevivência do núcleo familiar. Agregam-se ainda os valores morais impostos pela sociedade, e desse modo, a fim de dar respostas ao imaginário social $^{4}$ do casamento perfeito e feliz, muitas mulheres submetem-se, silenciadas, a situações rotineiras de violência, "mostrando que a família é mais importante do que o sujeito", como salienta Nader (2006, p. 236).

A inconsistência de dados efetivos sobre a violência de gênero é ainda maior em cidades localizadas no interior do país. Mesmo com a criação de mecanismos de denúncia e da agenda de políticas públicas e programas vinculados à mulher, muitas vivem silenciadas, sob um continuum de agressões de diversas formas. O Mapa da Violência (WAISELFISZ, 2015), constatou a interiorização da violência contra a mulher no Brasil e divulgou a evolução dos homicídios de mulheres nas capitais e nos municípios brasileiros. $\mathrm{O}$ estudo apresenta uma estimativa do número de feminicídios ${ }^{5}$ (assassinatos por motivo de gênero), dada a entrada em vigor da nova Lei 13.104/2015, que inclui o feminicídio no rol dos crimes hediondos. A pesquisa do Mapa da Violência apresentou o ordenamento dos 100 municípios brasileiros com mais de 10.000 habitantes do sexo feminino, com as maiores taxas médias de homicídio de mulheres (por 100 mil). Os resultados dessa investigação identificaram que os municípios com as maiores taxas de assassinato de mulheres são os de pequeno porte, muito espalhados ao longo do território nacional (WAISELFISZ, 2015, p. 26), o que confirma a interiorização da violência contra as mulheres no país. Apesar dessa constatação, ainda são escassos os trabalhos acadêmicos voltados para o estudo da violência contra as mulheres em cidades

\footnotetext{
${ }^{4}$ O historiador polonês Bronislaw Baczko define o imaginário social como um conjunto de representações coletivas constituindo pontos de referência pelas quais a coletividade direciona regras e comportamentos. Sobre o assunto ver: BACZKO, 1985.

${ }^{5}$ Os estudos que abordam as mortes de mulheres utilizam os conceitos de femicídio e feminicídio para definirem os crimes praticados contra as mulheres. Pasinato faz uma revisão bibliográfica de trabalhos produzidos na América Latina que abordam as categorias "femicídio" e sua variante "feminicídio". A autora reconhece que tais conceitos carecem de melhor formulação, no entanto, alega que mais importante do que a questão conceitual, é distinguir os femicídios de crimes comuns, como estratégia para prevenir a impunidade. Isso porque nos casos de femicídios persiste a ideia da opressão das mulheres pelos homens, demonstrando que os códigos patriarcais ainda estão fortemente marcados na sociedade. Para a autora, sempre que a morte de uma mulher apresenta-se como um ponto final de um continuum de terror, deve ser considerada como femicídio. Imbutido nesse conceito estão as ideias de que as mortes das mulheres estariam relacionadas ao não cumprimento de seus papéis sociais, conforme normatizada pela sociedade patriarcal e que, também, resultariam da discriminação baseada em gênero, já que é descrito como um crime cometido por homens contra mulheres, seja individualmente, seja em grupos. No femicídio os motivos das mortes não estão relacionados à raça/etnia, geração, filiação religiosa ou política. Já a definição de "feminicídio" foi dada por Marcela Lagarde que considera que ocorre quando o Estado não garante a segurança das mulheres ou cria um ambiente no qual não estão seguras em suas comunidades ou lares. Estão relacionados ao feminicídio, segunda a autora, a impunidade, a omissão, a negligência e a conivência das autoridades do estado, razão pela qual considera o feminicídio como um crime de estado. Sobre o assunto ver: Pasinato (2011) e Lagarde (2006).
} 
interioranas. Pouco se sabe a respeito daquelas mulheres que vivem em contextos rurais ou em locais situados no interior do Brasil, e sobre a situação em se encontram.

É por essa razão que o recorte geográfico do presente estudo o faz peculiar. A idiossincrasia de estudar a violência no interior do Brasil, numa região na qual os comportamentos são influenciados por rígidas normatizações conservadoras, fez percorrer auspiciosos caminhos em busca de relatos de mulheres que sofreram violências de companheiros, namorados ou maridos. Assim sendo, buscando investigar a realidade da violência contra a mulher no interior de Minas Gerais, esse estudo seguiu fios e $\operatorname{rastros}^{6}$ da pesquisa de Mestrado "A filiação sindical rural da mulher: fator de empoderamento?" (AMORIM, 2012), realizada entre 2010 e 2012. Por meio dos indícios que emergiram daquele estudo, de que existe um alto índice de violência na cidade, velado e socialmente fechado no espaço doméstico, optou-se por analisar de que forma o patriarcado $^{7}$ influencia no comportamento de homens e mulheres em Carangola que leva ao silenciamento dos casos de violência conjugal.

Desse modo, buscando dar respostas às razões do silenciamento da violência contra a mulher em Carangola, desde 2016 a pesquisadora vem seguindo os indícios de ocultação da violência doméstica nesta cidade. A investigação histórica que se faz é sustentada pelo sentido hierárquico do patriarcado presente na convivência entre as pessoas dessa cidade, a qual reforça a presença da violência de gênero e, talvez pelo fato de inexistir uma Delegacia Especializada de Atendimento à Mulher (DEAM) no município, a hipótese deste estudo é de que há um alto índice de violência na cidade, velado e socialmente fechado no espaço doméstico, contudo predomina o silêncio que permeia essas relações violentas entre muitos homens e mulheres.

Trilhando os indícios do silenciamento e com referência na afirmação de Ginzburg (1990) de que "se a realidade é opaca, existem zonas privilegiadas - sinais, indícios - que permitem decifrá-la", para além dos dados da pesquisa de mestrado realizada por Amorim (2012), foram utilizados os registros do Sistema de Informação de Agravos de Notificação

\footnotetext{
${ }^{6}$ Menção ao texto de Carlo Ginzburg no qual diz que o "fio do relato ajuda-nos a orientarmos no labirinto da realidade". Sobre o assunto ver: GINZBURG, 2007, p. 7.

${ }^{7}$ Lana Lima e Suellen Souza na obra "Dicionário Crítico de Gênero", publicada em 2015, traçam uma definição para o conceito de patriarcado e ressaltam que a palavra se origina da combinação dos vocábulos gregos pater (pai) e arkhe (origem, comando), e que a expressão se refere a uma forma de organização familiar e social em que um homem, o patriarca, submete os outros membros da família ao seu poder. Frisam que, não obstante as mudanças porque passam a organização familiar no mundo contemporâneo, o modelo patriarcal ainda desempenha, não somente no Brasil, importante papel na estruturação das relações conjugais de gênero, legitimando as desigualdades de direitos entre homens e mulheres. Sobre o assunto ver: LIMA; SOUZA, 2015. $\mathrm{p}, 515$.
} 
(SINAN) $^{8}$, da cidade de Carangola, referentes aos anos de 2014 e 2015. Esses números informam os atendimentos no Sistema Único de Saúde (SUS) por violência doméstica contra crianças, mulheres e idosos e são compulsoriamente notificados pelas unidades de saúde. Os dados supracitados compilam que, para esta cidade, dentre os anos de 2014 e 2015 ocorreram 76 casos relacionados a violências físicas, psicológicas, sexuais e morais. Tais registros permitem inferir que, em uma localidade com população feminina estimada pelo Instituto Brasileiro de Geografia e Estatística (IBGE) (BRASIL, 2010) em 16.604 mulheres, existem silenciamentos nos casos de violência de gênero, o que se leva a questionar as razões para tal.

Em busca de respostas para essa indagação foram estudados dez casos, ou seja, dez mulheres que viveram situações de violência de gênero foram analisadas. A indicação da maioria dessas entrevistadas foi realizada por intermédio do Centro de Referência Especializado de Assistência Social (CREAS) ${ }^{9}$, já que o município não possui Delegacia Especializada no Atendimento à Mulher (DEAM) e os casos são atendidos pela única Delegacia de Polícia local e encaminhados para o Ministério Público, que por sua vez, direciona as mulheres para atendimentos psicossociais no CREAS.

Destaca-se que para este estudo optou-se, de forma criteriosa, por buscar informações amparadas em registros como o cadastro de mulheres atendidas pelo CREAS, vítimas de violência de gênero e a base de dados do SINAN que informa o número de casos de violência contra a mulher, atendidos pela Rede Pública de Saúde. Essa escolha se ampara não pela crença na judicialização dos casos, mas por acreditar que esses mecanismos formais engendram redes de apoio ao enfrentamento à violência, fundamentais contra o isolamento que dificulta ainda mais a situação das mulheres da cidade de Carangola. Por se tratar de uma cidade do interior de Minas Gerais, o acesso aos serviços de atendimento especializado tornase mais penoso, ainda mais quando se trata de assistência social pública.

\footnotetext{
${ }^{8}$ Considerado uma forma de identificar o número de casos de violências ocorridas nos municípios brasileiros, o SINAN fornece os registros de atendimento no Sistema Único de Saúde (SUS) por violência doméstica contra crianças, mulheres e idosos. A notificação da violência doméstica, sexual e/ou outras violências foi implantada no SINAN, do Ministério da Saúde, em 2009. O registro deve ser realizado de forma universal, contínua e compulsória, nas situações de suspeita ou confirmação de violências envolvendo crianças, adolescentes, mulheres e idosos, atendendo às Leis 8.069 (Estatuto da Criança e Adolescente), 10.741 (Estatuto do Idoso) e 10.778 (notificação compulsória de violência contra a mulher), quando do atendimento ambulatorial das mulheres nos hospitais e unidades de Pronto Atendimento. A notificação é realizada pelo gestor de saúde do SUS, mediante o preenchimento de uma ficha de registro específica. Sobre o assunto ver: WAISELFISZ, 2015, p. 12.

${ }^{9}$ O CREAS é uma unidade pública estatal, de abrangência municipal ou regional, referência para a oferta de trabalho social a famílias e indivíduos em situação de risco pessoal e social, por violação de direitos, que demandam intervenções especializadas no âmbito do Sistema Único de Assistência Social (SUAS). Sobre o assunto ver: BRASIL, 2011.
} 
Contudo, percebeu-se que era necessário buscar situações de violência contra a mulher que não haviam sido notificadas pela Rede de Saúde (dados do SINAN), pelo CREAS e nem mesmo pela Delegacia de Polícia. Para tanto, procurou-se conhecer conjunturas para além daquelas direcionadas pela equipe do CREAS, levando-se em consideração a premissa de que a influência do patriarcado, sobretudo em cidades de pequeno porte, é determinante para o silenciamento da violência contra a mulher. Isto é, buscava-se encontrar mulheres que ainda não haviam realizado denúncias contra seus maridos, companheiros ou ex-companheiros agressores. Assim, foi feito cálculo amostral para aplicação de questionários, distribuídos aleatoriamente em diferentes pontos da cidade, a fim de encontrar casos de violência silenciados pelas vítimas. O cálculo da amostra levou em conta a população feminina local, que o IBGE estimou em 16.604 mulheres e chegou-se ao número de 376 questionários, cálculo amostral que considerou $95 \%$ de margem de confiança ${ }^{10}$.

Nesse modo, elaborou-se um questionário fechado contendo doze questões que abordam indagações relacionadas à violência contra a mulher. Foi garantido o anonimato das entrevistadas, mediante Termo de Consentimento Livre e Esclarecido (TCLE) submetido e aprovado pelo Comitê de Ética de Pesquisa do Centro de Ciências da Saúde (CEP/CCS/UFES). Salienta-se que, para atingir a totalidade de 376 questionários respondidos, distribuiu-se 550 formulários. Muitos deles não retornaram ou tiveram que ser descartados por insuficiência de questões respondidas.

As doze questões do formulário são divididas em duas partes. Na primeira, trata-se do perfil das entrevistadas ${ }^{11}$, na qual se argui sobre idade, profissão, estado civil, escolaridade, região de residência (se zona urbana ou rural) e renda. A segunda parte aborda questões específicas que objetivavam avaliar a existência de uma relação conjugal violenta. Para isso se arguiu sobre o grau de relevância do casamento, sobre como avalia a situação atual do relacionamento conjugal, o que mais desagradada na relação, se já havia pensado em se separar e, em caso afirmativo, quais seriam as razões que a levaram a pensar dessa forma. Caso tivesse pensado em separação, o que havia feito. Outra questão do formulário abordava se havia denunciado o companheiro por agressão, se sofreu agressão de membros da família e,

\footnotetext{
${ }^{10}$ Para o cálculo amostral utilizou-se a fórmula da proporção finita dada por Bolfarine e Bussab (2005).

${ }^{11}$ Para a aplicação dos questionários fechados, não houve o intuito em delinear características étnicas e nem religiosas das entrevistadas. Isso porque se temeu que houvesse algum tipo de resistência no preenchimento ou na devolução dos formulários preenchidos. Desse modo, os questionários não aludiam à tais abordagens porque o enfoque maior está na análise da violência doméstica/conjugal associada ao contexto social em que se encontram. Ou seja, este estudo se volta para a especificidade da violência contra mulheres que residem em uma cidade cujo tipo de sociabilidade impacta no silenciamento. Aspectos relacionados a etnia e a religião aumentariam o número de variáveis de análise e poderiam trazer vieses que não nos interessam, neste momento.
} 
em caso afirmativo, quem agrediu. Por fim, se indagava se a mulher estava amparada por medida protetiva.

Para atingir o objetivo de conhecer casos de violências contra a mulher, ainda não notificados na Rede Pública de Saúde e nem na Delegacia de Polícia, a última pergunta do questionário arguia que em caso de a entrevistada ter sofrido algum tipo de violência (física, psicológica, sutil, sexual, moral ou patrimonial) se aceitaria conceder um relato. Caso quisesse participar de uma entrevista em profundidade, deveria registrar seu número de telefone, para que fosse contatada para a realização da mesma. Obviamente, não é surpreendente o fato de somente nove mulheres mencionarem que gostariam de participar de uma entrevista para relatar sobre a violência a que estavam submetidas. No entanto, após os contatos por telefone, somente duas concederam entrevistas, que somadas às oito entrevistadas que já haviam sido realizadas, totalizaram as dez entrevistas do estudo.

Este artigo se limita a apresentar alguns dados resultantes do survey, os quais foram tratados estatisticamente com apoio do software R 3.5, que permitiu compreender as opiniões e as atitudes das mulheres que participaram do estudo. A aplicação de questionários nas pesquisas sociais é indicada como método de pesquisa, conforme salienta Babbie (1999), pois esse método pode ser resumido em três passos: 1) coleta e quantificação de dados; 2) sistematização dos dados coletados em banco de dados, e 3) realização de análise após a coleta para confirmação de teorias.

\section{O local do estudo e a relação entre o tipo de sociabilidade e o silenciamento da violência contra a mulher.}

O município no qual a pesquisa se desenvolveu dista aproximadamente $360 \mathrm{~km}$ de Belo Horizonte, capital do estado, e se localiza, geograficamente, na porção sudeste do Estado de Minas Gerais, na região da Zona da Mata, formada por sete microrregiões e 142 municípios. Situa-se no chamado Vale do Carangola, na confluência com os Estados do Rio de Janeiro e Espírito Santo, a cerca de $40 \mathrm{~km}$ das divisas desses estados, respectivamente, as cidades de Porciúncula e Dores do Rio Preto, conforme demonstra a Figura 1. 
Figura 1 - Mapa da cidade de Carangola - MG

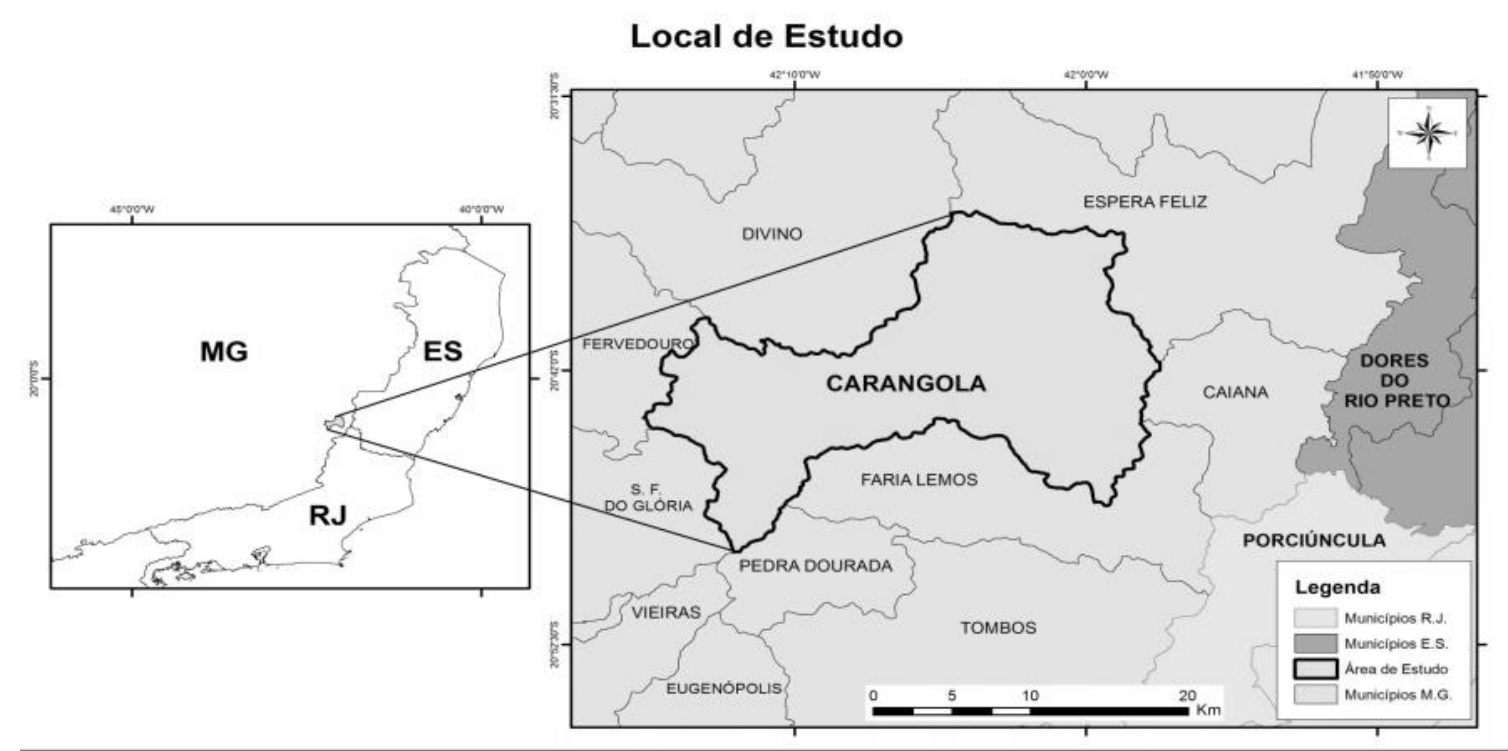

Fonte: Elaborado pela pesquisadora (2016).

A cidade se distingue pelo tipo de sociabilidade, já que a presença do mundo rural e a dinâmica social local faz com que a localidade tenha atributos de cidade de pequeno porte. Sobre a classificação de cidades, Sposito (2006) admite que, mais do que a classificação populacional que tão somente as definiria como cidade de porte médio ou de pequeno porte, cabe analisar o entendimento sobre suas características e seus cotidianos. Para a autora, são chamadas 'cidades de porte médio' aquelas que têm entre 50 mil e 500 mil habitantes. Contudo, não se pode conceituá-las como cidades médias apenas empregando o elemento demográfico, ou seja, para a observação de uma cidade pequena há que se considerar aspectos como a divisão do trabalho e estilos de vida, com a interação entre os valores rurais e urbanos no cotidiano da população, que apesar de ser urbana, vivenciam e reproduzem valores e práticas características do mundo rural. A autora cita, como exemplo, as práticas das relações de trabalho, de consumo, hábitos alimentares e o vínculo identitário com o lugar, fortemente presentes no cotidiano local (SOARES; MELO, 2010).

O tipo de sociabilidade desse lócus de estudo diz muito a respeito dos dados notificados sobre a violência contra a mulher e, também, sobre como os casos de violência são silenciados pelas vítimas. A análise da violência contra a mulher em Carangola, no que se refere a sociabilidade, se ampara nas discussões téorico-conceituais de Norbert Elias. Na obra "A sociedade dos indivíduos" (1994), Elias ajuda a compreender as estruturas sociais da localidade estudada. O autor oportuniza a reflexão de como a presença constante de outras pessoas e sua proximidade representa o controle do comportamento individual e o crescente 
autocontrole em todas as esferas da vida e são pessoas que representam a comunidade, tais como vizinhos, comerciantes e mesmo os próprios parentes, enfim um grande número de atores sociais que convivem entre si. No caso específico da violência contra a dignidade da mulher, tais atores podem, por alguma razão, terem presenciado ou apenas terem conhecimento do processo de violência de uma mulher, uma vez que a proximidade entre as pessoas, dado o reduzido número de habitantes faz com que os indivíduos dividam os mesmos espaços de convivência e se conheçam, apesar de não serem amigos próximos.

Elias (1994) declara que as relações entre as pessoas são determinadas pelas estruturas e leis sociais e, por isso, deve-se pensar na estrutura como um todo, para compreender como se formam as partes individuais, ou seja, como agem as pessoas inseridas numa dada realidade social. Assim, cada mulher que silencia a violência sofrida, além dos fatores relacionados com a convivência pessoal com o agressor, afetividade, medo ou dependência financeira, o julgamento da sociedade representa, para essa moradora da cidade, o principal fator de ocultação sobre as agressões. Desse modo, o comportamento dos indivíduos dessa sociedade determina o silenciamento sobre a violência contra mulher.

Outro aspecto relevante para se observar a ocultação sobre a convivência conjugal violenta em uma cidade pequena se ampara em comentários maliciosos, tais como os apresentados por Elias e Scotson na obra “Os estabelecidos e os Outsiders” (2000). Os autores registram a pesquisa feita no final dos anos 50, numa pequena escala de análise, que chamam de microcosmo, de uma comunidade de periferia urbana, nomeada ficticiamente de Winston Parva. Analisam o comportamento da comunidade que forma esse povoado industrial, dividindo a população do lugar em dois grupos. Um que se reconhecia como estabelecido, fundado na concepção de antiguidade na ocupação do lugar, e outro grupo formado por recém-chegados, denominado outsiders. Entre eles havia relações de poder e o controle social $^{12}$ era feito por meio da fofoca, termo utilizado pelos autores. No capítulo "Observações sobre a fofoca", Elias e Scotson fazem considerações sobre mexericos (ELIAS; SCOTSON, 2000 , p. 113) e como a boataria representa um fator de entretenimento para determinadas sociedades. Nesse capítulo definem a fofoca como "informações mais ou menos depreciativas sobre terceiros, transmitidas por duas ou mais pessoas uma às outras" (ELIAS; SCOTSON, 2000, p. 121). Na alegação dos autores a informação veiculada pela fofoca é transmitida

\footnotetext{
${ }^{12}$ No que se refere ao controle social leva-se em conta o papel das instituições (família, escola, religião) que influenciam nas relações de sociabilidade e na reprodução de valores e orientações para a ação social. Nader aponta que tais instituições promoveram, na História do Brasil, o processo moralizante e o destino biológico da mulher. Sobre o assunto ver: NADER, 2001, p. 71.
} 
oralmente entre os membros da comunidade e com uma velocidade considerável, a fim de permitir que as notícias se espalhem pela comunidade na qual é gerada.

O uso da escala reduzida de análise para estudar a comunidade pequena de Winston Parva constitui um paradigma para o estudo realizado em Carangola, que de forma semelhante, investiga a violência de gênero em uma cidade com aspectos de cidade de pequeno porte, pois, segundo Elias e Scotson (2000):

o uso de uma pequena unidade social como foco da investigação de problemas igualmente encontráveis numa grande variedade de unidades sociais maiores e mais diferenciadas, possibilita a exploração desses problemas com uma minúcia considerável - microscopicamente, por assim dizer. Pode-se construir um modelo explicativo, em pequena escala, da figuração que se acredita ser universal - um modelo pronto para ser testado, ampliado e, se necessário, revisto através da investigação de figurações correlatas em maior escala. Nesse sentido, o modelo de uma figuração estabelecidos-outsiders que resulta da investigação de uma comunidade pequena, como a de Winston Parva, pode funcionar como uma espécie de "paradigma empírico" (p. 20-21).

Ou seja, para os autores, o paradigma empírico de relações estabelecidos-outsiders contribui para uma compreensão melhor da dinâmica das relações sociais

uma vez que esse tipo de estudo engloba num mesmo conceito guarda-chuva certos tipos de relações que tradicionalmente só são percebidos como diferentes (...) e pode-se ver com clareza, por exemplo, o papel desempenhado nas relações estabelecidos-outsiders pelas diferenças entre as normas e, em especial, entre os padrões de autocontrole (ELIAS; SCOTSON, 2000, p. 49).

Dessa maneira, o estudo que os autores realizaram sobre a especificidade de Winston Parva é norteador para a análise das relações sociais na cidade de Carangola, sobretudo a respeito de como influenciam no silenciamento das violências de gênero. Naquela investigação, os estudiosos identificaram o alto grau de coesão das famílias entre as duas comunidades analisadas, os estabelecidos e os outsiders. Destacam a função dos mexericos como instrumento de rejeição infalível assim como realçavam, em alguns casos, a superioridade da conduta, dos valores e do estilo de vida de determinados segmentos dos dois grupos pesquisados, numa dinâmica de controle social.

O contexto no qual as mulheres pesquisadas estão inseridas acarreta singularidades que refletem a construção social de culturas masculinas e femininas marcadas por relações de poder assimétricas e, ainda uma imagem idealizada sobre as relações conjugais. A esse cenário soma-se à situação de submissão e dominação, o espectro da vergonha e a dificuldade de tomar decisões por si ou de conceber qualquer pensamento sem a constante referência ao grupo. 
Elias (1994, p. 108) disserta que a cidade pequena é um daqueles lugares onde "a pessoa não tem oportunidade, nem capacidade de ficar só" e, em tais situações, a composição do indivíduo se adapta ao constate convívio com os outros a quem o comportamento tem que ser ajustado. Assim, há um crescente domínio comportamental pelos membros das famílias, da vizinhança e da comunidade em todas as esferas da vida. Dado a essa característica, reconhecer a violência sofrida, falar a respeito dela e denunciar agressões representam atos de rupturas com os padrões sociais da localidade. Do mesmo modo, agir com violência para disciplinar ações é dar uma resposta ao papel social masculino, exigido pela comunidade, que direta ou indiretamente, cobra do homem um posicionamento viril ${ }^{13}$ a respeito de atos e condutas disciplinares, seja entre homens ou entre homens e mulheres.

Do mesmo modo, o controle dos comportamentos e ações por parte da comunidade foi observado no estudo de Comerford (2015), que pesquisou alguns municípios da Zona da Mata de Minas Gerais, região onde está localizada a cidade de Carangola. Identificou o controle de deslocamentos e associações a parentescos, numa sistemática de "vigiar e narrar" como:

\begin{abstract}
a cuidadosa observação dos muitos movimentos cotidianos entre roças, casas e localidades, de suas direções, velocidades e permanências, dos agrupamentos de pessoas, das suas atitudes e expressões quando agrupadas, dos deslocamentos excepcionais (por envolverem estranhos, por se tratar de trânsitos inusitados, extemporâneos, furtivos, etc.), fornece rica matériaprima acrescentada às inúmeras conversas em que essas pessoas se situam, posicionam e julgam mutuamente, mesmo enquanto discutem assuntos aparentemente distantes, neutros ou banais (p. 31).
\end{abstract}

Infere-se, portanto, que o ato de vigiar, julgar e narrar é uma característica cultural de comunidades ou cidades pequenas. Nesse sentido, a observação inculca o julgamento, principalmente no que diz respeito a aspectos do mundo privado das famílias.

Em Carangola, de acordo com o apontado por Elias (1994), a mobilidade das pessoas no sentido espacial e social é menor e é inescapável o envolvimento com grupos de parentesco e a comunidade local. Aonde quer que o indivíduo vá, sempre há alguém que o conhece ou que é seu parente. Logo, o monitoramento social é exercido sobre a mulher que sofre violência ao longo de todo o processo, que envolve desde o ato em si até o momento em que se dirige a única delegacia de polícia da cidade para registrar uma ocorrência contra

\footnotetext{
${ }^{13}$ A virilidade é entendida como capacidade reprodutiva, sexual e social, mas também como aptidão ao combate e ao exercício da violência (sobretudo em caso de vingança). Em oposição a mulher, cuja honra, essencialmente negativa, só pode ser defendida ou perdida, sua virtude sendo sucessivamente a virgindade e a fidelidade, o homem "verdadeiramente homem" é aquele que se sente obrigado a estar à altura da possibilidade que lhe é oferecida de fazer crescer sua honra buscando a glória e a distinção na esfera pública. Sobre o assunto ver: BOURDIEU, 2017, p. 76.
} 
seu/sua agressor/a. Destaca-se que o transporte público não atende a região onde está situada a Delegacia de Polícia Civil.

Como já mencionado, em comunidades nas quais os laços sociais são mais intensos, como Carangola, o tipo de sociabilidade favorece a vigilância e o controle, sobretudo da mulher, que conforme a hierarquia patriarcal de gênero deve ser adestrada. A vigilância da comunidade pode representar fator de influência para o silenciamento da violência, atitude de passividade incorporada através da educação feminina voltada para a virtude, a honestidade e a discrição.

\section{Rompendo o silenciamento}

Com objetivo de encontrar informações sobre a violência doméstica em Carangola, rompendo o silenciamento sobre os casos, bem como a subnotificação dos mesmos, as questões dos formulários aplicados versavam sobre temas que envolvem a violência contra a mulher e sua relação com a vida conjugal. Buscou-se, ainda, traçar uma perspectiva geral do perfil das entrevistadas e os números apontam que aproximadamente $40 \%$ das participantes do estudo possuem idades entre 20 a 29 anos, sendo 50,41\% casadas e 36,86\% solteiras. Apenas 7,32\% das mulheres se divorciaram.

No que tange as indagações sobre a relação das mulheres com seus parceiros, foi questionada a opinião referente à relevância do casamento para a vida da mulher. Conforme a Figura 2, o percentual de 45,74\% entrevistas consideram o casamento importante e $27,66 \%$ como muito importante, somando assim aproximadamente $75 \%$ do total. Essa opinião se mantém independente do estado civil.

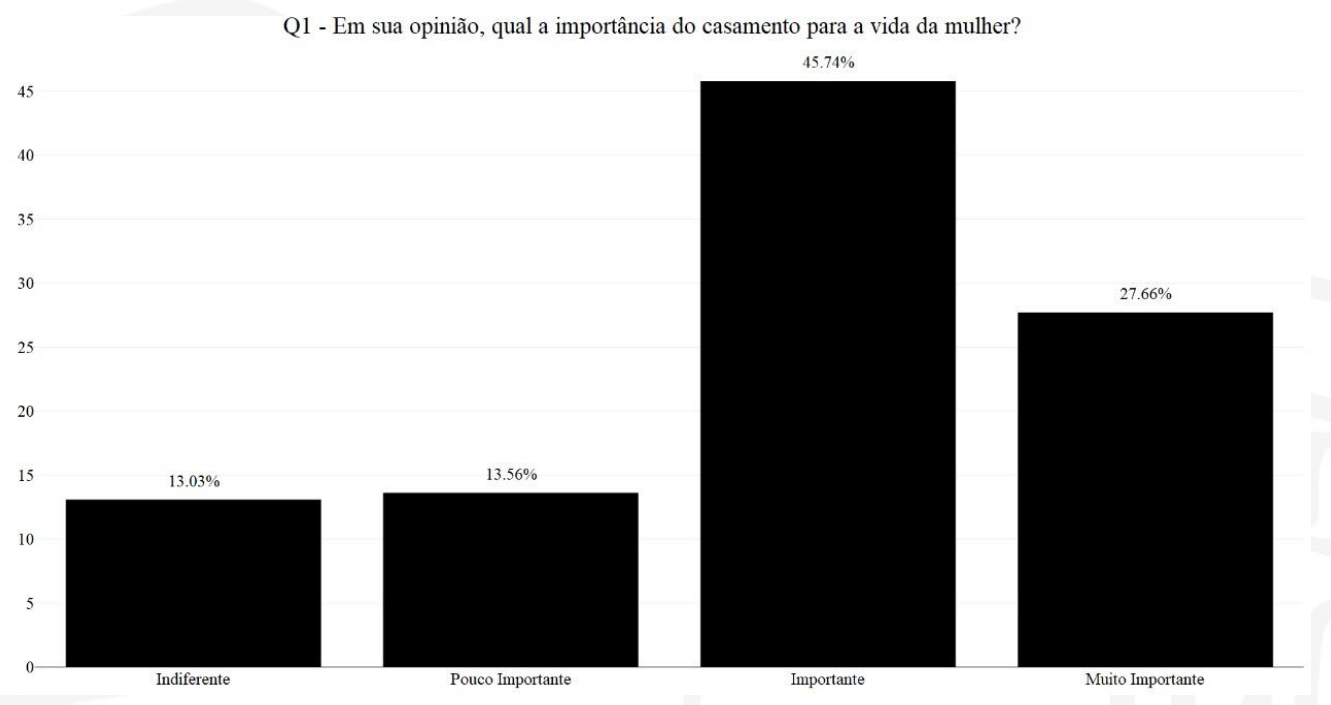

Figura 2 - Gráfico de frequência das respostas quanto à questão 1. Fonte: Dados da pesquisa (2018).

Caminhos da História, v.23, n.1 (jan./jun.2018) 
Quando se correlaciona esses dados ao percentual de entrevistadas que se divorciaram $(7,32 \%)$ percebe-se que as mulheres carangolenses valorizam o casamento enquanto instituição. A historiografia do Brasil destaca que o ideal do matrimônio como destino "natural" da mulher foi implantado desde o período colonial, como forma de contribuir para a dominação econômica e política e para manter características culturais da Metrópole, muito influenciadas por dogmas religiosos católicos. Segundo Nader, mesmo com a intensificação da urbanização, "no século XIX, o casamento ainda representava, pelo menos para uma pequena parcela da população, a união de interesses na manutenção do prestígio e da estabilidade social" (2008, p. 121). Posteriormente, no século XX, ainda com a modernização da infraestrutura das cidades e a mudança nos costumes sociais, a sociedade sofreu a intervenção do Estado na manutenção do casamento e da família, "enfatizando a responsabilidade feminina sobre o progresso da humanidade as mulheres foram induzidas a aceitar como sua obrigação a constituição de famílias modernas e higiênicas e assumir o papel de Rainhas do lar", como disserta Nader (2008, p. 130).

Quando o assunto é casamento, mais uma vez chamam atenção os dados da pesquisa, resultantes das questões que arguem sobre a satisfação da vida conjugal e o que mais agrada e o que mais desagrada no relacionamento. As respostas encontradas dão conta de que 81,65\% das mulheres que participaram do estudo se consideram felizes no casamento. Quanto ao que mais valorizam na relação conjugal, 67,13\% apontaram o amor e o companheirismo do parceiro e, entre os fatores que mais desagradam, os mais mencionados foram falar alto com a mulher, com 60,22\% e impedir de fazer algo que gostam, com 21,01\%. Os números relacionados ao amor do companheiro demonstram a incorporação da ideia de que o casamento é lugar privilegiado para o amor, concepção que foi ressignificada no século $\mathrm{XX}$, a fim de atender aos preceitos de uma sociedade higiênica. $\mathrm{O}$ amor estava relacionado ao prazer e a sexualidade e passou a ser considerado conveniente para a manutenção da estabilidade no espaço doméstico. Desse modo, para as mulheres carangolenses, o casamento é entendido como ideal feminino correspondendo a crença de "a mulher só seria feliz se estivesse ligada a um homem por meio do matrimônio" (NADER, 2008, p. 137).

No entanto, de forma contraditória, ao responderem a questão seis Já sentiu vontade de se separar? $58,67 \%$ das mulheres entrevistadas destacam que possuem ou possuíam vontade de se separar de seus companheiros e as causas mais apontadas para isso foram o menosprezo, com $36,93 \%$ e a humilhação, com $21,57 \%$. Essas duas formas de violência se 
enquadram na categoria de violência sutil, discutida por Nader (2006). Trata-se de um tipo de violência abstrata, impalpável, que não deixa marcas no corpo físico e apenas é percebida pela pessoa que a experimenta. Firma-se em "tratamentos grosseiros dos homens para com as mulheres e práticas humilhantes e constrangedoras dentro do próprio espaço doméstico" (NADER, 2006, p. 241). Traduz-se também pela solidão no casamento, resultado do desprezo do parceiro e que se transforma na violência sutil do distanciamento e da separação dentro de casa.

Mostram-se controversos os números apontados pela maioria das entrevistadas, pois ao responderem as primeiras questões do survey disseram ser felizes no casamento $(81,65 \%)$ e que o amor e o companheirismo de seus parceiros eram fatores de maior satisfação no relacionamento. Ora, onde estão a felicidade e o amor nessas relações conjugais, já que os números da pesquisa evidenciam aspectos opressores no convívio com o parceiro? Reconhecer a vivência num relacionamento com abusos poderia contrariar o imaginário social de um casamento feliz? Isso poderia influenciar na decisão de tornar o fato público através de denúncia? O tipo de sociabilidade do município de Carangola teria relação com o silenciamento sobre a realidade de um relacionamento conjugal violento?

As respostas para tais questionamentos começam a surgir quando, perseguindo a ideia do silenciamento sobre vivências em contextos conjugais violentos, analisou-se a questão sete do formulário aplicado. Essa pergunta se tornou parâmetro principal para encontrar respostas que pudessem constatar a realidade da violência conjugal das mulheres entrevistadas. Indagou-se no referido quesito "O que te levou a pensar numa separação?”, apresentando como opções de respostas a categorização dos tipos de violência à integridade da mulher, de acordo com a classificação dada pela Lei Maria da Penha, já mencionadas no início deste artigo. Assim, somadas as respostas para agressão, ameaça, destruição de objetos, humilhação, menosprezo e violência sexual, tem-se que 96,42\% das razões apontadas como motivadoras para separação estão relacionadas a atos que configuram violência, conforme se pode constatar pela Figura 3. 
Q7 - 0 que te levou a pensar numa separação?

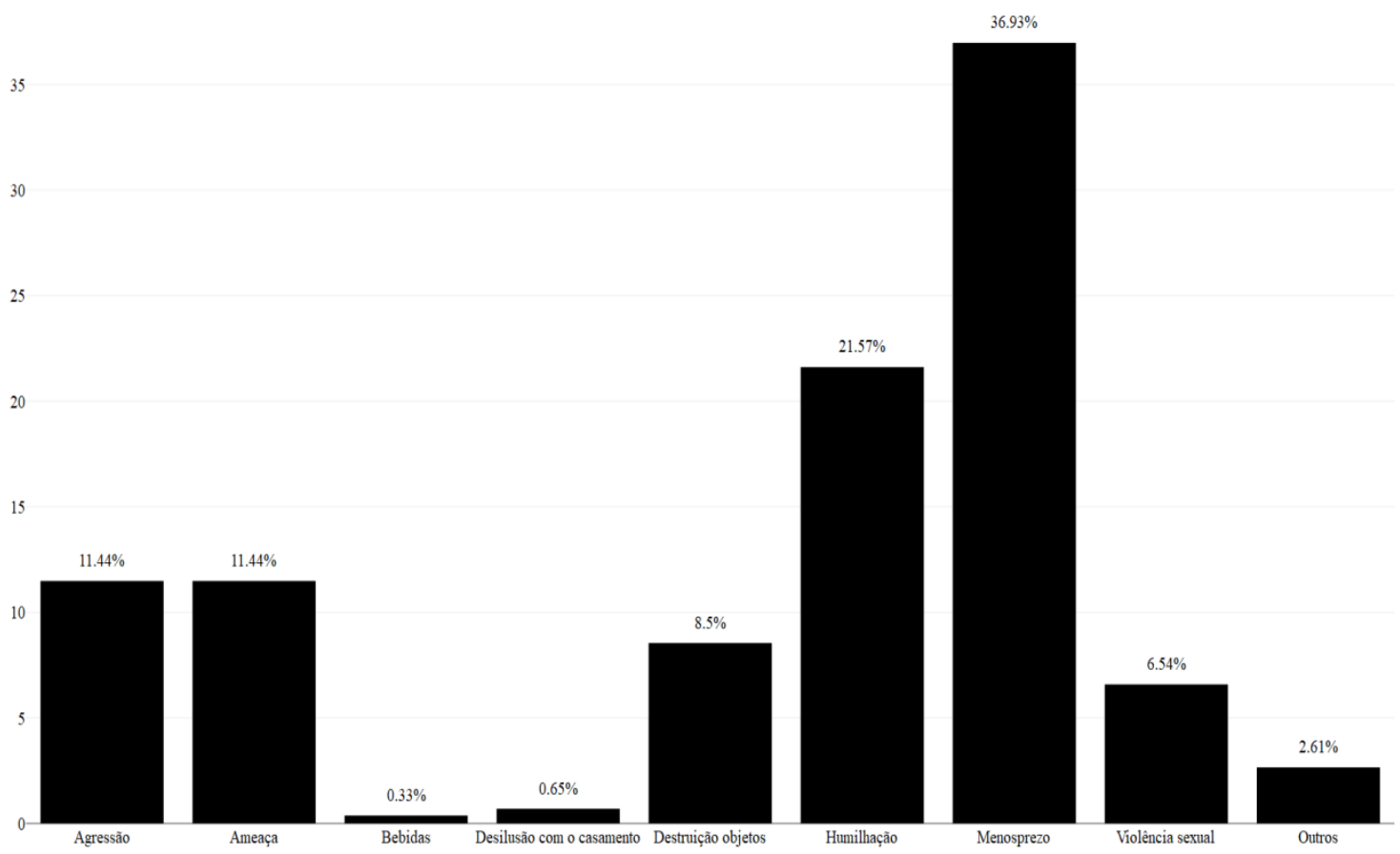

Figura 3 - Gráfico de frequência das respostas quanto à questão 7. Fonte: Dados da pesquisa (2018).

Observa-se ainda pela Figura 3, que apenas três opções de respostas não se enquadram em tipos de violência contra a mulher, como bebidas, desilusão com o casamento e outros. Enfatiza-se que as entrevistadas escreviam nos formulários, à mão, alternativas que não constavam no questionário, como, por exemplo, más companhias, influência da família no relacionamento e uso de drogas e, a fim de facilitar a análise dos dados, tais respostas foram todas agrupadas na categoria outros. Ressalta-se que responderam a essa pergunta as mulheres que estão dentro do percentual de 58,67\% que afirmaram que pensaram em se separar. Esse número representa mais da metade do grupo entrevistado. Desse modo, as entrevistadas que pensaram em se separar sofreram, de fato, violência conjugal e compõem a maioria das entrevistadas.

$\mathrm{Na}$ questão nove que perguntava "Se você já sofreu alguma agressão de seu companheiro (ou ex-companheiro), já realizou alguma denúncia na Delegacia de Polícia Civil?", apenas $8,5 \%$ responderam que fizeram denúncias. Ao cruzar essa resposta com a da questão sete, identificou-se que dentre as que denunciaram, $30 \%$ sofreram agressões físicas e $15 \%$ ameaças. As que pensaram em se separar devido à violência sexual $(6,54 \%)$, não prestaram denúncia.

A violência praticada pelo parceiro íntimo, dado a sua especificidade, é oculta e difícil de ser mensurada estatisticamente. No entanto, pesquisas realizadas pela OMS em 11 países 
sobre a saúde da mulher e a violência doméstica (GARCIA-MORENO, 2005) indicam que 15 a $71 \%$ das mulheres sofrem violência física e/ou sexual por um parceiro íntimo em algum momento de suas vidas. Por meio da violência sexual os homens atribuem ao corpo feminino um sentimento de posse e, em defesa da honra recorrem à força a fim de disciplinar gestos, ações e atitudes que julgam fora de suas referências normativas. $\mathrm{O}$ corpo da mulher, visto como propriedade masculina e instrumento de poder é o campo no qual o homem defende sua honra, canaliza suas frustrações como, por exemplo, a falta de dinheiro e/ou desemprego. Desejado, dominado, subjugado, os corpos femininos se fazem território de dominação, instrumento de poder masculino. Seguindo esse sentido de privilégio, o homem impõe o dever de afirmar, em toda e qualquer circunstância, sua virilidade (BOURDIEU, 2017, p. 76). Baseada na visão androcêntrica, a qual estabelece o corpo feminino como território de dominação masculina, há o favorecimento da naturalização de uma ordem social fundada em práticas sexuais impostas, não consensuais.

Retomando a análise dos dados sobre as mulheres que afirmaram o interesse em se separar, levando-se em consideração que mais da metade das participantes do estudo demonstrou intuito no rompimento conjugal, é fundamental compreender quais as principais razões que fizeram com que elas tenham desistido (pergunta oito do questionário). Dentre as respostas obtidas, o principal motivo é a vergonha perante a família e a sociedade (33,33\%), sendo ainda que $12,04 \%$ relataram que desistiram devido serem financeiramente dependentes dos companheiros, conforme demonstra a Figura 4, a seguir.

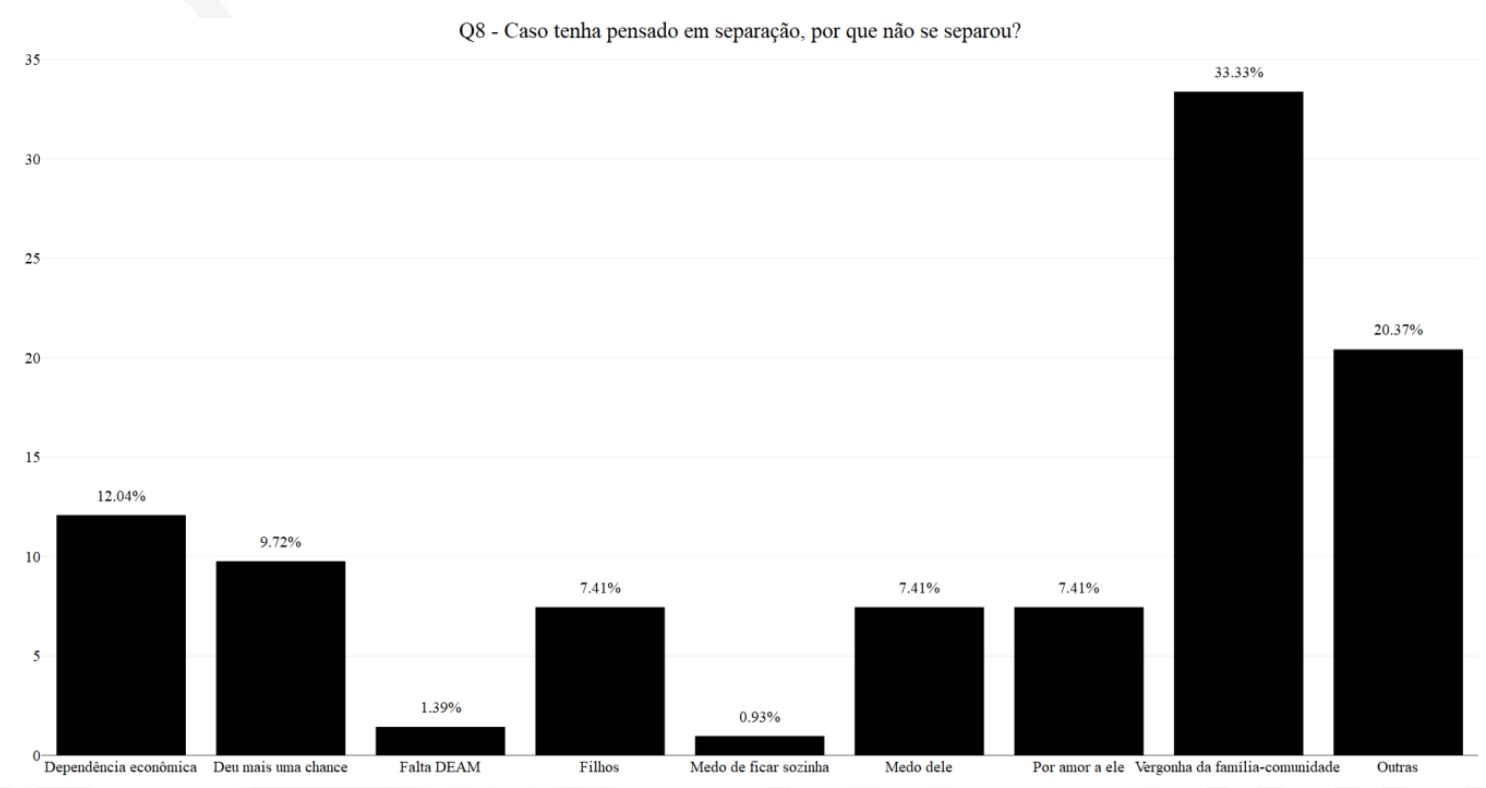

Figura 4 - Gráfico de frequência das respostas quanto à questão 8.Fonte: Dados da pesquisa (2018). 
Observa-se pelos dados apresentados na Figura 4, que a maior preocupação das mulheres que não denunciaram seus agressores é a vergonha da família/comunidade, o que possibilita afirmar que o tipo de sociabilidade local está diretamente relacionado ao silenciamento das mulheres que vivem em relações conjugais violentas.

A proximidade entre as pessoas reforçam um dos medos que impedem algumas mulheres de abandonarem maridos abusivos: o impacto da pergunta " $O$ que as pessoas vão dizer?" (MILLER, 1995) Em resposta a temida indagação, a sociedade poderá julgar que a mulher não cumpriu seu papel de subserviência, tolerância, submissão. Que não foi uma boa mãe, uma boa esposa e, por isso, envergonha a família e a comunidade e representa um risco de influenciar o comportamento de outras mulheres.

No que tange ao medo do agressor, as informações resultantes do survey aplicado às moradoras de Carangola informam que dentre as mulheres que disseram que não se separaram por medo do companheiro, todas foram agredidas fisicamente ou ameaçadas. Essa análise foi obtida pelo cruzamento das questões sete e oito.

A passividade e o medo intimidam a ação das mulheres gerando interpretações de complacência e conivência com os agressores e representam papel relevante no ciclo da violência, pois agravam o continuum de agressões, cada vez mais frequentes e mais intensas. O medo está categorizado dentre os fatores considerados inibidores da chamada Rota Crítica ${ }^{14}$ que a mulher agredida percorre antes de realizar a denúncia. A rota das mulheres em situação de violência inicia com a decisão de romper o silêncio e denunciar. No entanto, antes disso necessitam compreender que estão sofrendo violência, já que a sociedade educa a mulher para a submissão e naturaliza o uso da violência entre os gêneros, especialmente nas relações conjugais. A intimidação se constitui como ferramenta do patriarcado para demonstrar que o medo é uma característica feminina e, também, para reproduzir no espaço privado da casa a hierarquia dos gêneros, colocada na "ordem das coisas" (BOURDIEU, 2017, p. 21). Essa expressão utilizada por Bourdieu denota a divisão dos sexos no mundo social, incorporada nos corpos e nos habitus dos agentes funcionando como sistemas de percepção, de pensamento e de ação. Do mesmo modo, o medo se funda como virtude negativa da mulher, dada pela representação da dominação masculina.

\footnotetext{
${ }^{14} \mathrm{O}$ estudo de Montserrat Sagot sobre "Rotas Críticas de Mulheres afetadas pela violência intrafamiliar, realizado em dez países da América Latina” busca conhecer os fatores que impulsionam o início de uma chamada rota crítica, que é quando a mulher decide apropriar-se de sua própria vida e busca ajuda para levar adiante sua decisão de romper com situações de resignação e violência. Na pesquisa de Sagot, levou-se em consideração contextos sociais locais para buscar respostas para a violência intrafamiliar, problema social de grandes dimensões que constitui entraves para o desenvolvimento socioeconômico, consiste em grave violação aos Direitos Humanos e é favorecido pela invisibilidade ou subnotificação de casos, por ser considerado um problema de foro privado. Sobre o assunto ver: SAGOT, 2000.
} 
Novamente fazendo referência às entrevistadas do estudo, daquelas que denunciaram seus companheiros, menos de $20 \%$ estão sob alguma medida protetiva, o que denota que a falta de atenção adequada pode contribuir para que elas não se exponham ao risco de denunciar e ficar sem proteção. A pesquisa "Rotas críticas: a trajetória das mulheres no enfrentamento às violências", realizada por Meneghel (2007) na cidade de Porto Alegre constatou que as mulheres declaram fragilidades e limitações na aplicação da lei Maria da Penha e salientam o descumprimento das medidas protetivas pelos agressores e a dificuldade dos serviços de segurança pública efetivamente protegê-las.

De modo semelhante, pode-se crer que o mesmo ocorra em Carangola, pois para além do medo de represálias dos agressores soma-se a falta de centros de atendimento integral para mulheres em situação de violência, capazes de realizar trabalhos de prevenção e reabilitação. Especificamente nesta cidade mineira, a inexistência de grupos de apoio à mulher vítima de violência favorece a égide do medo, dificulta o enfrentamento e o encorajamento para o rompimento da relação violenta, que aliada ao tipo de sociabilidade torna-se um ingrediente a mais para favorecer o silenciamento das mulheres. O recomeço, palavra de ordem na dinâmica da violência doméstica/familiar, torna-se mais penoso em uma cidade pequena, dado ao problema estrutural de falta de rede de apoio, majorados pelo comportamento social da comunidade, carregado de julgamentos decorrentes de uma estrutura social pautada em rígidos códigos patriarcais.

\section{Considerações finais}

Conforme apresentado, a violência conjugal na cidade de Carangola ainda é um assunto velado, pois ao analisar os dados dos 376 questionários aplicados percebeu-se que as entrevistadas que participaram do estudo tentaram burlar as respostas apresentadas pelo formulário, na tentativa de silenciar experiências conjugais opressoras ou violentas. Nas primeiras questões, afirmaram que estavam satisfeitas com o relacionamento conjugal e que o amor do companheiro era o que mais as agradava. Contudo, à medida que as perguntas avançavam surgiam as contradições entre as respostas.

Pelo exame das informações colhidas pelo survey, conclui-se que o casamento é relevante para as mulheres de Carangola independentemente do atual estado civil, ou seja, solteiras, casadas, divorciadas, em união estável e viúvas consideram o casamento importante $(73,4 \%)$ e, talvez por isso, o percentual de mulheres divorciadas é de 7,32\%. Supõe-se ainda 
que, pela valorização que dão ao matrimônio, sejam tolerantes com situações de violência conjugal, vivenciadas no dia a dia.

No que se refere a violência, o percentual de mulheres que sofreram qualquer tipo de agressão é de 69,19\%, sendo que 12,06\% foram agredidas fisicamente pelo companheiro, ou seja, as entrevistadas discernem se são atos de violência física ou não. Quando se considera que a agressão partiu do companheiro ou de amigos/familiares a taxa de mulheres agredidas chega a $70,74 \%$.

Apenas $8,5 \%$ das mulheres fizeram denúncias, sendo que dessas queixas, pouco mais da metade $(55,17 \%)$ foi devido à agressão física, levando-se a crer que há tolerância quanto a outros tipos de agressões, principalmente aquelas que não deixam vestígios no corpo.

A vergonha da família/comunidade é o principal motivo para que as mulheres não efetivem a separação (33,33\%). Pode-se afirmar ainda, que a vergonha de reconhecer a situação de violência na qual estão inseridas, também fez com que tentassem mascarar suas respostas nos formulários da pesquisa, pois quando das primeiras perguntas se diziam satisfeitas na relação, graças ao amor e o companheirismo de seus parceiros. Essas opiniões se mostraram divergentes com o avanço das respostas. Esse dado que aponta a vergonha em se separar, aliado ao número de mulheres que tinham a intenção de romper a relação conjugal, são relevantes para o estudo, já que evidenciam que a proximidade e a presença constante da comunidade influenciam no comportamento de homens e mulheres de Carangola. No que se refere aos homens, o tipo de sociabilidade reforça o caráter da dominação masculina e ações sob a égide da violência. Para as mulheres restam a submissão e o silêncio. O tipo de sociabilidade da cidade foi considerado uma variável que indicava relação com o silenciamento da violência conjugal e corrobora com a afirmação de que os rígidos códigos patriarcais locais ainda estão incorporados nas famílias carangolenses, tornando as mulheres reféns de relações conjugais violentas em nome da preservação do ideal de matrimônio feliz. Pode-se afirmar a realidade dessas mulheres não difere das de outras, mundo afora, pois perpassam ao adestramento para o matrimônio, a crença fundada no amor e nos afetos, que originam uniões indissolúveis e a convivência com um cotidiano de opressão.

\section{Referências bibliográficas}

AMORIM, Érika Oliveira. A sindicalização rural da mulher: fator de empoderamento? 2012. 158 f. Dissertação (Mestrado em Instituições sociais e desenvolvimento; Cultura, processos sociais e conhecimento). Universidade Federal de Viçosa, Viçosa, 2012.

BABBIE, Earl. Métodos de Pesquisas de Survey. Belo Horizonte: Editora UFMG, 1999. 
BACZKO, B. Imaginação social. In: Enciclopédia Einaudi. Antropos-Homem. Lisboa: Imprensa Nacional, Casa da Moeda, 1985.

BOLFARINE, H.; BUSSAB, W. O. Elementos de Amostragem. São Paulo: Edgar Blücher, 2005.

BOURDIEU, Pierre. A dominação masculina. Tradução Maria Helena Kühner. Rio de Janeiro: Bestbolso, 2017.

BRASIL. IBGE. Censo Demográfico, 2010. Disponível em: < https://cidades.ibge.gov.br/brasil/mg/carangola/panorama>. Acesso em: 12 ago. 2018.

. Lei Maria da Penha. Lei n. 11.340/2006. Coíbe a violência doméstica e familiar contra a mulher. Presidência da República, 2006.

COSTA, Jurandir Freire. A inocência e o vício: estudos sobre o homoerotismo. 3 ed. Rio de Janeiro: Relume Dumará, 1992.

COMERFORD, John. Córregos em movimento: famílias, mapeamentos e assuntos na Zona da Mata mineira. In: COMERFORD, John; CARNEIRO, Ana; DAINESE, Graziele (Orgs.). Giros etnográficos em Minas Gerais: casa, comida, prosa, festa, política, briga e o diabo. Rio de Janeiro: 7 Letras: FAPERJ, 2015.

ELIAS, Norbert. A sociedade dos indivíduos. Tradução Vera Ribeiro. Rio de Janeiro: Zahar, 1994.

ELIAS, Norbert; SCOTSON, John L. Os estabelecidos e os outsiders: sociologia das relações de poder de uma pequena comunidade. Rio de Janeiro: Jorge Zahar, 2000.

GARCIA-MORENO, Claudia et al. Multi-Country study on women's health and domestic violence against women. Geneva, World Health Organization. 2005.

GINZBURG, Carlo. Sinais: raízes de um paradigma indiciário. In . Mitos, Emblemas e Sinais. São Paulo: Cia. das Letras, 1990.

O fio e os rastros. Verdadeiro, falso, fictício. Tradução de Rosa Freire d'Aguiar e Eduardo Brandão. São Paulo: Companhia das Letras, 2007.

GROSSI, Miriam Pillar. Rimando amor e dor: reflexões sobre a violência no vínculo afetivoconjugal. In: PEDRO, Joana Maria e GROSSI, Miriam Pilar. (Orgs.). Masculino, feminino, plural: gênero na interdisciplinaridade, Florianópolis, Mulheres, 1998.

LAGARDE, Marcela. Por la vida y la libertad de las mujeres. Fin al feminicidio. In: RUSSEL, Diana E. H. y HARMES, Roberta A. (eds.). Feminicídio: una perspectiva global. Traduzido por Guillermo Vega Zaragoza. México, CIICH, UNAM, 2006.

LIMA, Lana Lage da Gama; SOUZA, Suellen André de. Patriarcado. In: COLLING, Ana Maria; TEDESCHI. Losandro Antônio. (Org.). Dicionário Crítico de Gênero. Dourados-MS: Ed. UFGD, 2015.

MENEGHEL, S. N. Rotas críticas: a trajetória das mulheres no enfrentamento das violências [Projeto de Pesquisa]. Porto Alegre: Apoio CNPq, 2007.

MILLER, Mary Susan. Feridas invisíveis: abuso não-físico contra mulheres. Tradução de Denise Maria Bolanho. São Paulo: Summus, 1995.

NADER, Maria Beatriz. Violência sutil contra a mulher no ambiente doméstico: uma nova abordagem de um velho fenômeno. In: SILVA, Gilvan Dutra da; NADER, Maria Beatriz; FRANCO, Sebastião Pimentel (Orgs.). História, mulher e poder. Vitória: EDUFES; PPGHis, 2006, p. 236.

. Paradoxos do progresso: a dialética da relação mulher, casamento e trabalho. Vitória: Edufes, 2008.

PASINATO, Wania. "Femicídios" e as mortes de mulheres no Brasil. Cad. Pagu, n.37, Campinas, July/Dec., 2011.

SAFFIOTI, Heleieth. Gênero, patriarcado e violência. São Paulo: Expressão Popular: Fundação Perseu Abramo, 2015. 
SAFFIOTI, Heleieth; ALMEIDA, Suely. Violência de Gênero: poder e impotência. Rio de Janeiro, Revinter, 1995.

SAGOT, M. Ruta critica de las mujeres afectadas por la violencia intrafamiliar en América Latina: estudios de caso de diez paises. San José: Organización Panamericana de la Salud; 2000.

SPOSITO, M. A. Loteamentos fechados em cidades médias paulistas. In: SPOSITO, E. S.; SPOSITO, M. E. B; SOBARZO, O. (Org.). Cidades médias: produção do espaço urbano e regional. São Paulo: Expressão Popular, 2006.

SOARES, Beatriz Ribeiro; MELO, Nágela Aparecida de. Cidades médias e pequenas: reflexões sobre os desafios no estudo dessas realidades socioespaciais. In: LOPES, Diva Maria Ferlin; HENRIQUE, Wenderl (Orgs.). Cidades médias e pequenas: teorias, conceitos e estudos de caso. Salvador: SEI, 2010.

TELES, Maria Amélia de Almeida; MELO, Mônica de. O que é Violência contra a Mulher. São Paulo: Brasiliense, 2002.

WAISELFISZ, Julio Jacobo. Mapa da Violência 2015. Homicídio de Mulheres no Brasil. ONU Mulheres / Organização Pan-Americana da Saúde / Organização Mundial da Saúde / Secretaria Especial de Políticas para as Mulheres / Faculdade Latino-Americana de Ciências Sociais. Brasília, 2015. 